\title{
Comparing plasma bubble occurrence rates at CHAMP and GRACE altitudes during high and low solar activity
}

\author{
C. Xiong ${ }^{1,2}$, J. Park ${ }^{1,3}$, H. Lühr ${ }^{1}$, C. Stolle ${ }^{1,4}$, and S. Y. Ma ${ }^{2}$ \\ ${ }^{1}$ Helmholtz Centre Potsdam, GFZ German Research Centre for Geosciences, Telegrafenberg, 14473 Potsdam, Germany \\ ${ }^{2}$ Department of Space Physics, College of Electronic Information, Wuhan University, Wuhan 430079, China \\ ${ }^{3}$ Department of Physics, Korea Advanced Institute of Science and Technology (KAIST), Daejeon, Korea \\ ${ }^{4}$ National Space Center, Technical University of Denmark, 2100 Copenhagen, Denmark
}

Received: 3 March 2010 - Revised: 30 July 2010 - Accepted: 10 August 2010 - Published: 6 September 2010

\begin{abstract}
Based on the multi-year data base (2001-2009) of CHAMP Planar Langmuir Probe (PLP) data and GRACE K-Band Ranging (KBR1B) data, typical features of ionospheric plasma irregularities are studied at the altitudes of CHAMP $(300-400 \mathrm{~km})$ and GRACE $(\sim 500 \mathrm{~km})$. The phenomena we are focusing on are the equatorial plasma bubbles (EPBs). Similar seasonal/longitudinal (S/L) distributions of EPB have been found at both CHAMP and GRACE altitudes during solar active and quiet years. Peak EPB occurrence rates, defined as number of events within an $\mathrm{S} / \mathrm{L}$ bin divided by the number of passes over that bin, decrease from the high and moderate solar flux period (2001-2005) to the low solar flux period (2005-2009) from $80 \%$ to $60 \%$ and $60 \%$ to $40 \%$ at CHAMP and GRACE altitudes, respectively. On average the occurrence rate increases linearly with solar flux at about the same rate at CHAMP and GRACE. For high flux levels (P10.7> 200) non-linear increases are observed at GRACE. The occurrence rate increases rapidly after 19:00 local time (LT) during high solar flux periods. Around solar minimum rates increase more gently and peak around 22:00 LT. The highest occurrence rates are encountered at latitudes around $10^{\circ}$ north and south of the dip equator. Results from the two altitudes support the notion that EPBs form regions of depleted plasma along geomagnetic fluxtubes. It is shown for the first time that in regions of high occurrence rates EPBs are associated with fluxtubes reaching greater apex heights than those in regions of low rates.
\end{abstract}

Keywords. Ionosphere (Equatorial ionosphere; Ionospheric irregularities)

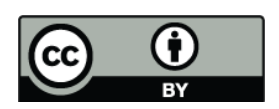

Correspondence to: C. Xiong (xiongchao@whu.edu.cn)

\section{Introduction}

The term equatorial plasma bubble (EPB) stands for a localized region of plasma density depletion in the nighttime low-latitude F-region (e.g. Kelley, 1989). The global distribution of EPBs has been studied for decades, and a typical seasonal/longitudinal (S/L) distribution was deduced from satellite measurements. Maruyama and Matuura (1984) obtained a full S/L distribution of EPBs analyzing topside ionograms onboard the ISS-b satellite from 1978 to 1980. During June (December) solstice the occurrence rate reaches highest values in African and Pacific (south America and Atlantic) regions. During equinoxes the occurrence rate is generally higher, and the longitudinal variation is smaller than that during solstices. Using the Atmospheric Explorer-E (AE-E) satellite ( $\sim 300-400 \mathrm{~km}$ altitude) data from 1977 to 1981 Kil and Heelis (1998) investigated EPB climatology. Occurrence of EPBs above $350 \mathrm{~km}$ altitude exhibits a clear $\mathrm{S} / \mathrm{L}$ dependence which is consistent with that of Maruyama and Matuura (1984). The EPB occurrence rate is generally higher at the altitudes below $300 \mathrm{~km}$ than above $350 \mathrm{~km}$, and the former occurs over a broader longitude ranges. Huang et al. (2001) and Burke et al. (2004) analyzed the Defense Meteorological Satellite Program (DMSP) (840 km altitude) data, and obtained similar S/L distribution as described above. Park et al. (2005), using the Korea Multi-Purpose Satellite-1 (KOMPSAT-1, $680 \mathrm{~km}$ altitude at 22:40 LT), and Su et al. (2006, 2007), using Formosa Satellite-1/Republic of China Satellite-1 (FORMOSAT-1/ROCSAT-1, $600 \mathrm{~km}$ altitude), obtained similar S/L distribution of EPBs around the solar maximum in 2001. Using the magnetic signature accompanying the EPBs, Stolle et al. (2006) performed a comprehensive statistical study of EPBs. They used the fluxgate

Published by Copernicus Publications on behalf of the European Geosciences Union. 
magnetometer (FGM) data onboard CHAMP (350-450 km altitude) from 2001 to 2004. Their results also reveal that the most severe occurrence rate of EPBs is observed above Africa and the Pacific Ocean (South America) around June (December) solstice months.

Tsunoda (1985) proposed the occurrence of plasma instabilities to peak during times when the solar terminator (dependent on season) is well aligned with the geomagnetic meridian (dependent on longitude). Fejer et al. (1999) have used incoherent scatter radar measurements over Jicamarca to examine the effects of quiet-time and disturbance vertical plasma drifts on the generation and evolution of 3-m equatorial $\mathrm{F}$ region irregularities for different levels of solar activity. They deduced the day-to-day, seasonal, and the solar cycle variability of spread $\mathrm{F}$ occurrence over Jiacmarca, as well as the dependence on magnetic activity. They argued that the variability of EPB occurrence can be explained by the associated variation of the equatorial vertical plasma drift. Stolle et al. (2008), using magnetic signatures of EPB, have presented global evidence for the direct relationship between EPB and the vertical plasma drift. The EPB occurrence rate showed closer relation to the vertical plasma drift velocity integrated from the afternoon minimum $(\sim 17: 00 \mathrm{LT})$ to the drift reversal point $(\sim 19: 00 \mathrm{LT})$ than to the peak velocity during the pre-reversal enhancement (PRE).

Huang et al. (2002) have mentioned that the DMSP satellite detected more EPB events during high solar activity years. Also, enhanced scintillation activity was found during solar maximum compared to solar minimum years (Basu et al., 2002). Stolle et al. (2006), using the magnetic signatures accompanying EPBs, deduced a close relationship between the EPB occurrence rate and solar Extreme Ultra Violet (EUV) flux.

According to Kil and Heelis (1998), EPB occurrence rates maximize at the magnetic equator above $350 \mathrm{~km}$ altitude, as observed by AE-E satellite. The latitudinal distribution below $300 \mathrm{~km}$ altitude becomes complex with the emergence of off-equatorial peaks. Stolle et al. (2006) found that the latitudinal distribution of EPBs detected by CHAMP $(\sim 400 \mathrm{~km}$ altitude) peaks at $\pm 9.5^{\circ}$ magnetic latitude with a standard deviation of $4.5^{\circ}$ in both hemispheres. The EPB occurrence rate deduced from ROCSAT-1 observations at $600 \mathrm{~km}$ altitude peaks at the geomagnetic equator and decreases symmetrically to $\pm 20^{\circ}$ magnetic latitude (Burke et al., 2004).

The characteristic EPB occurrence rate versus local time (LT) has also been studied. According to Kil and Heelis (1998) the EPB occurrence rate above $350 \mathrm{~km}$ altitude increases rapidly between 19:00 and 21:00 LT and decays slowly after midnight. The occurrence rate below $300 \mathrm{~km}$ altitude increases more slowly with local time. Stolle et al. (2006), using data of the years 2001-2004, report that the occurrence increases rapidly between 19:00 LT and 19:30 LT and the highest rates are observed between 21:00 LT and 22:00 LT at CHAMP altitudes. It decays gently after 23:00 LT, and the shape of the local time distribution curve is quite similar to that found by Burke et al. (2004), whose results are based on plasma depletion observations at the ROCSAT-1 altitude.

Although there have been a large number of reports on the EPB climatology, there still remains room for further investigations. Most of the studies cited above investigated periods around the solar maximum period, when EPB activity is known to be highest. While Huang et al. (2002) reported EPB climatology over a full solar cycle ( $\sim 11$ years) at $840 \mathrm{~km}$ altitude, little is known at lower altitudes, especially near the F-region peak $(\sim 400 \mathrm{~km})$, around the solar minimum. Kil and Heelis (1998) reported a significant dependence of EPB climatology on observation altitudes. However, EPB climatology at $300-400 \mathrm{~km}$ altitudes as described by Kil and Heelis (1998) only pertains to years of mediumto-high solar activity (1977-1981). Stolle et al. (2006) reported EPB climatology at $\sim 400 \mathrm{~km}$ altitude, but their results were also limited to years of medium-to-high solar activity (2001-2004).

In this paper we intend to fill the gap of EPB climatology as described above. We investigate simultaneous EPB detections by CHAMP $(\sim 400 \mathrm{~km}$ altitude $)$ and GRACE $(\sim 500 \mathrm{~km}$ altitude) separately for solar maximum and solar minimum conditions. The results will help to deduce the evolution and the 3-D morphology of depleted fluxtubes associated with EPBs. In the following sections, we first describe the electron density readings based on PLP data from CHAMP and on the KBR1B data from GRACE. Then, we introduce the method how to derive the average electron density between GRACE-A and GRACE-B with the KBR1B data. Subsequently, we present the results of EPB occurrence distribution at the two altitudes. Also the relationship between EPB occurrence rates and local time, and magnetic latitude has been studied. Finally, we discuss reasons for the similarities and differences of the two observations.

\section{Data}

The CHAMP (Challenging Mini-satellite Payload) satellite was launched on 15 July 2000 into a circular, near-polar (inclination $=87.3^{\circ}$ ) orbit with an initial altitude of about $450 \mathrm{~km}$ which has decayed to some $330 \mathrm{~km}$ in 2009 , as shown in Fig. 1. Its local time changes by about $5.5 \mathrm{~min}$ per day, sweeping all time zones in 131 days (Reigber et al., 2002). Among other instruments a Planar Langmuir Probe (PLP) takes in-situ measurements of electron density. The nominal PLP data rate is a 1s sweep every $15 \mathrm{~s}$.

The GRACE (Gravity Recovery and Climate Experiment) satellites, which comprises two spacecraft, GRACE-A and GRACE-B, were launched on 17 March 2002 into a nearcircular, polar (inclination $=89^{\circ}$ ) orbit with an initial altitude of about $490 \mathrm{~km}$. The two satellites follow each other at a distance of about $200 \mathrm{~km}$. The altitude of GRACE is quite stable, ranging between 460 and $480 \mathrm{~km}$ in 2009, as shown 


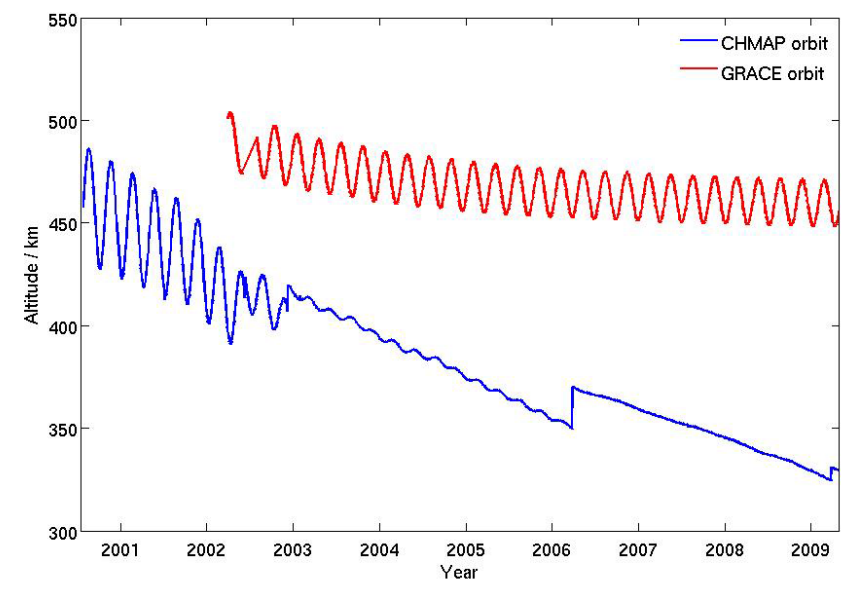

Fig. 1. The evolution of the ascending node altitude of CHAMP and GRACE from 2001-2009. The CHAMP orbit has decayed about $150 \mathrm{~km}$ and GRACE has decayed about $25 \mathrm{~km}$ during this time.

in Fig. 1. The local time of the orbit changes by about $4.5 \mathrm{~min}$ per day, sweeping all time zones in 160.5 days. The primary objective of the GRACE mission is to provide global highresolution models of the Earth's gravity field (Tapley et al. 2004). The instruments supporting our study are the K-Band Ranging System (KBR), and the GPS Space Receiver (GPS).

The K-Band Ranging System (KBR) system is the key science instrument of GRACE which measures the dual oneway range change between both satellites with a precision of about $1 \mu \mathrm{m}$ per second. From the KBR1B data we can get the change of Total Electron Content (TEC). In addition the GPS Navigation Data (GNV1B) can provide us the position of the two satellites. The nominal data rates of KBR1B and GNV1B are $5 \mathrm{~s}$ and $60 \mathrm{~s}$, respectively. From these data we can derive the average electron density between the two satellites, which we can use to study the plasma bubbles as we do with the CHAMP PLP data. Further details we will discuss in the next section.

\section{Retrieving electron density}

The KBR1B data provide the biased range, which is the true range plus an unknown bias, between the GRACE-A and GRACE-B spacecrafts. The bias is an arbitrary value for each piecewise continuous segment of phase change measurements and may change at arbitrary intervals. The reported biased ranges are corrected for ionospheric effects. The biased ionospheric correction is reported separately for the Ka band frequency, which contains also an arbitrary bias. Therefore, the correction indicates the change in ionosphere effect as a function of time [Case, et al., 2002; Bettadpur, 2007]. To calculate the change in ionospheric total electron content, $\triangle \mathrm{TEC}$, we use Eq. (1)
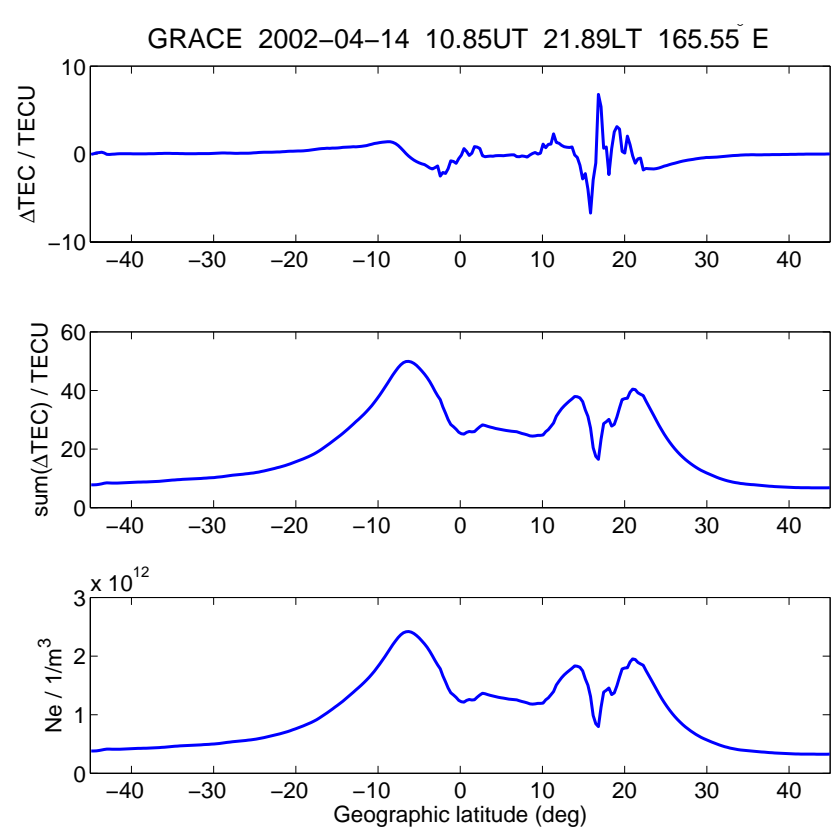

Fig. 2. Example of KBR1B data on 14 April 2004; $\triangle$ TEC (top panel), sum $\triangle T E C$ (middle panel) and average electron densitybetween GRACE-A and GRAC-B satellites (bottom panel).

$\Delta \mathrm{TEC}=-\left(d R \cdot f_{\mathrm{ka}}^{2}\right) /\left[40.3 \frac{s^{2}}{m^{3}}\right]$

where, $d R$ is the change in ionospheric range correction in $\mathrm{m}$ from KBR1B data, $f_{\mathrm{ka}}$ is the Ka band frequency in $\mathrm{Hz}$ $(32 \mathrm{GHz})$. The result is in TECU $\left(10^{16}\right.$ electrons $\left./ \mathrm{m}^{2}\right)$.

With the definition of $\triangle \mathrm{TEC}_{i}=\mathrm{TEC}_{i+1}$, if we add up the $\triangle \mathrm{TEC}_{i}$ values, we can obtain the horizontal TEC between GRACE-A and GRACE-B as described in Eq. (2)

$$
\begin{aligned}
\operatorname{sum}\left(\Delta \mathrm{TEC}_{n}\right)= & \sum_{i=1}^{n} \Delta \mathrm{TEC}_{i}=\sum_{i=1}^{n}\left(\mathrm{TEC}_{i+1}-\mathrm{TEC}_{i}\right) \\
= & \left(\mathrm{TEC}_{n+1}-\mathrm{TEC}_{n}\right)+\left(\mathrm{TEC}_{n}-\mathrm{TEC}_{n-1}\right)+\ldots \\
& +\left(\mathrm{TEC}_{2}-\mathrm{TEC}_{1}\right) \\
= & \mathrm{TEC}_{n+1}-\mathrm{TEC}_{1}
\end{aligned}
$$

As we can get the position information from GNV1B data, we obtain

$$
\begin{aligned}
\frac{\operatorname{sum}\left(\Delta \mathrm{TEC}_{n}\right)}{R_{n+1}} & =\frac{\mathrm{TEC}_{n+1}-\mathrm{TEC}_{1}}{R_{n+1}} \\
& =\frac{\mathrm{TEC}_{n+1}}{R_{n+1}}-\frac{\mathrm{TEC}_{1}}{R_{n+1}}=N e_{n+1}+C
\end{aligned}
$$

where, $i$ is the time index of data, $R_{i}$ is the distance and $N e_{i}$ is the average electron density between the two GRACE spacecraft. As the variation of $R_{i}$ is small, less than $5 \mathrm{~km}$ in one day, compared to the distance of GRACE-A and GRACE-B (180-220 km), we can consider $\mathrm{TEC}_{i} / R_{n+1}$ as a constant value, $C$ over a day, which is related to the first TEC 

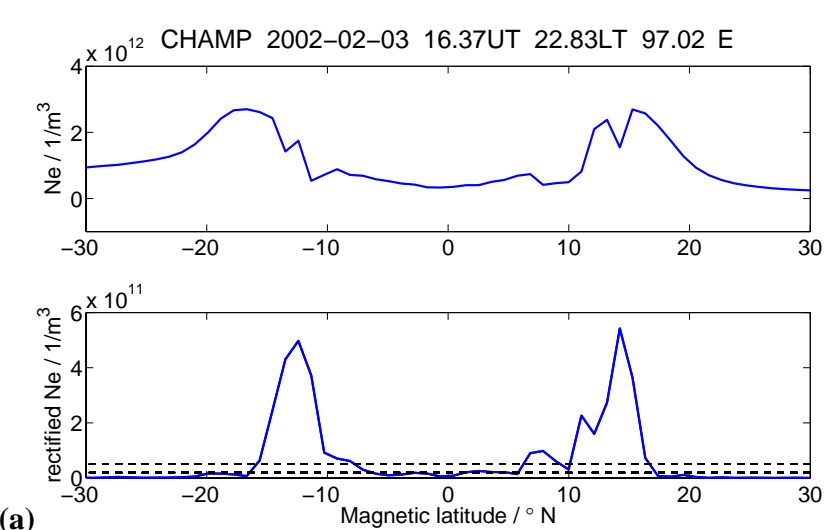

(a)
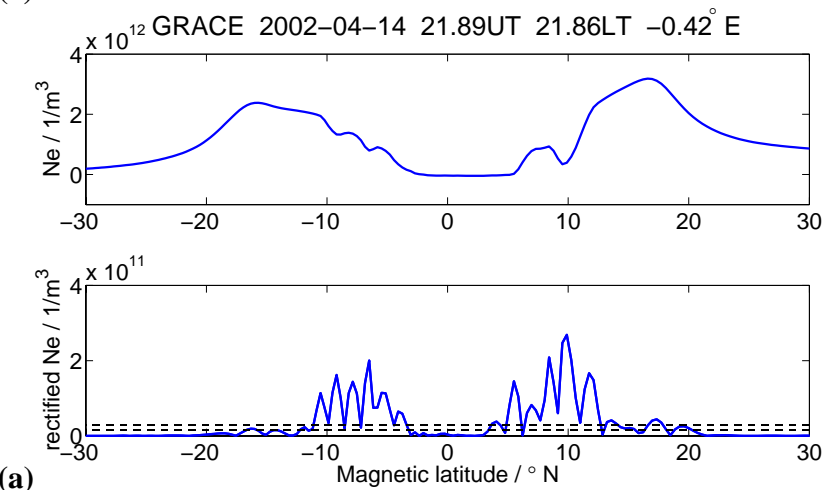

(a)

Fig. 3. Examples of bubble detected from PLP data and KBR data in the top and bottom frames, respectively. The dashed lines in both lower panels represent the upper (LU) and lower levels (LL) applied for the automatic EPBs detection process.

value of the piecewise continuous segment of phase change measurements. Figure 2 shows one example of averaged $\mathrm{Ne}$ between the GRACE spacecraft. For the detection of EPBs a constant bias of $\mathrm{Ne}$ is of no concern.

We use PLP observations from 9 years of the CHAMP mission (January 2001-November 2009) and the KBR1B from 8 years of the GRACE mission (April 2002-November 2009). To investigate the solar cycle dependence of the occurrence rate of EPBs and its global distribution, we have divided the data into two intervals: from 2001-2005 for high and moderate solar flux (mean F10.7 = $136.64 \mathrm{sfu}$ ) and 20052009 for low solar flux levels (mean F10.7 $=76.71 \mathrm{sfu}$ ). In the analysis we chose 5-year periods for comparison with F10.7 since this provides an even distribution of local time for all seasons. During a 5-year period the CHAMP satellite covers all local time sectors just 14 times and the GRACE satellites all local time sectors 11 times. For the following analyses, we will focus on the 18:00-04:00 LT sector as Stolle et al. (2006). Furthermore, we have selected data from quiet and moderately disturbed times when $\mathrm{Kp}<5.5$, to exclude effects of geomagnetic storm-related variations.

The PLP and KBR1B data have been divided into segments of equatorial crossings spanning the range of $-45^{\circ}$ to $45^{\circ}$ geographic latitude. We follow the approach of Stolle

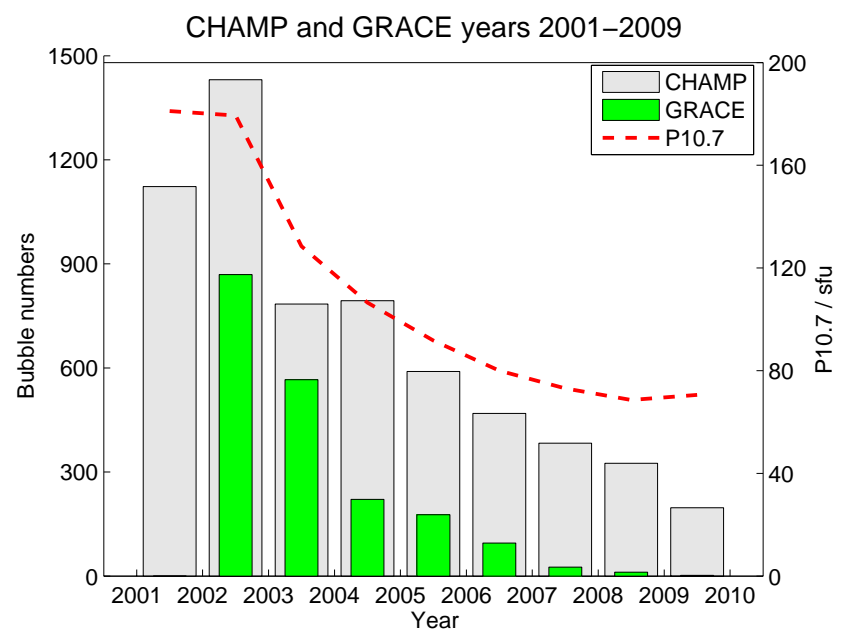

Fig. 4. EPB detections per year from CHAMP and GRACE observations for 2001-2009. The gray and green bars are the EPB numbers obtained from CHAMP and GRACE data, respectively, and the red dashed line represents the annual averages of solar activity.

et al. (2006) for detecting EPBs. Data from each equatorial orbit segment are high pass filtered with a cutoff period of $75 \mathrm{~s}$, after which the bias in GRACE average $\mathrm{Ne}$ is eliminated. This period corresponds to an along-track wavelength of $\sim 550 \mathrm{~km}$. Subsequently, the filtered signal is rectified.

The top and bottom frames in Fig. 3 show two examples of EPBs, respectively deduced from PLP and KBR1B data. Different limits are set for the thresholds applied to the data of CHAMP and GRACE, as $\mathrm{Ne}$ decays with altitude above the $\mathrm{F} 2$ peak. We have set an upper limit $(\mathrm{LU})=5 \times 10^{10} \mathrm{~m}^{-3}$, and a lower limit $(\mathrm{LL})=2 \times 10^{10} \mathrm{~m}^{-3}$ for CHAMP altitude and $\mathrm{LU}=3 \times 10^{10} \mathrm{~m}^{-3}, \mathrm{LL}=1.5 \times 10^{10} \mathrm{~m}^{-3}$ for GRACE altitude. For an EPB to be selected the rectified signal should have multi-peaked values above $\mathrm{LU}$, and the peaks should be surrounded by values below LL. The choice of these detection levels is by and large determined by the CHAMP PLP noise floor.

\section{Statistical study of EPB occurrences}

The long and continuous time series of CHAMP and GRACE provide an excellent opportunity for studying the various characteristics of EPBs in a statistical sense. Figure 4 shows the decreasing solar flux activity from 2001 to 2009 and the number of EPBs detected in every year by CHAMP and GRACE. In 2002 CHAMP and GRACE have encountered the most EPBs, and both satellites show a decreasing number of EPBs with decreasing solar activity. Based on our catalogue of detected EPB events we have investigated in a statistical study the various features of EPB occurrences.

We start with the seasonal/longitudinal (S/L) distribution. Detected EPBs are sorted into bins of 1 month by $10^{\circ}$ in longitude for the determination of occurrence rate. The number 
(a)

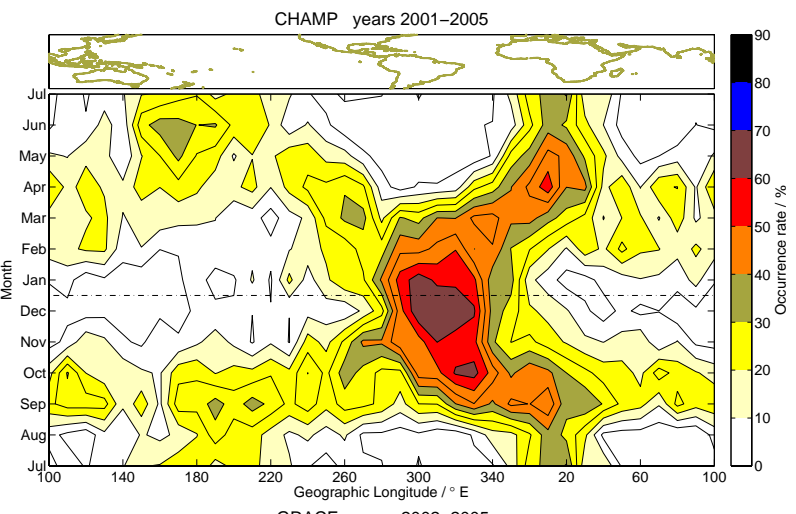

(b)

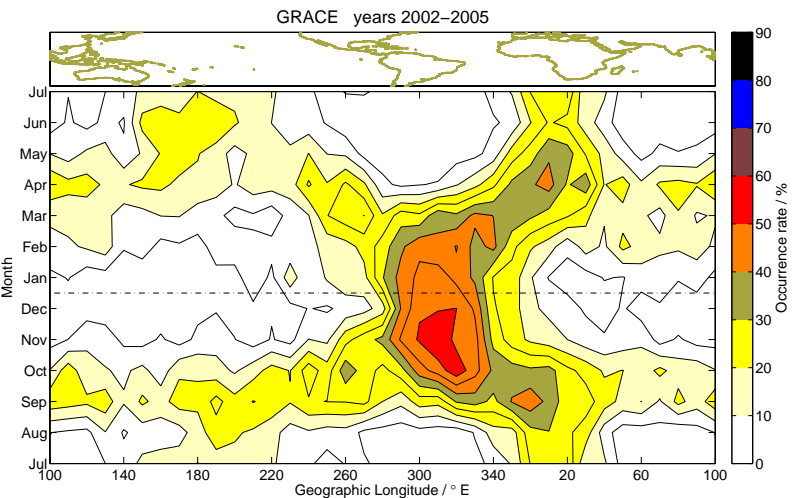

(a)

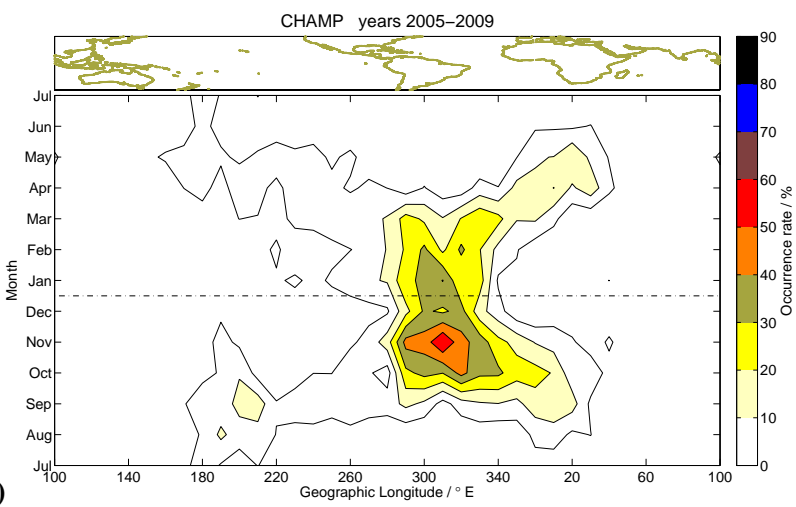

(b)

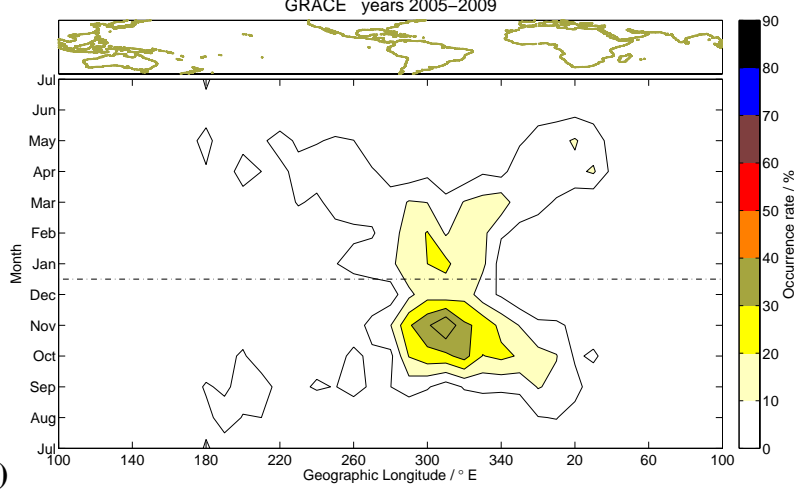

Fig. 5. The seasonal/longitudinal distribution of EPB occurrence rates from CHAMP PLP (top) and GRACE KBR (bottom) observations during high solar activity years (2001-2005). Bin sizes are one month by $10^{\circ}$ in longitude. The horizontal dashed line marks 1 January.

of events in one bin is divided by the total number of passes over that bin. The obtained distribution for enhanced solar activity years (2001-2005) resembles quite closely the ones presented by Burke et al. (2004) and Stolle et al. (2006). From Figs. 5 and 6, we can see that the EPB occurrence rates at CHAMP and GRACE altitudes have very similar S/L distributions both during high and low solar activity years. The largest occurrence rates of EPBs are observed above Brazil around December solstice months. On average over the high solar activity years occurrence rates reach up to $70 \%$ at the altitude of CHAMP (average attitude $380 \mathrm{~km}$ ) and it decays to $60 \%$ at the altitude of GRACE (average altitude $480 \mathrm{~km}$ ). Highest occurrence rates are observed from October to January. During the low solar activity years the average occurrence rates detected by the two satellites have reduced in this region, to about $60 \%$ by CHAMP and $40 \%$ by GRACE. Here, the highest occurrence rates above Brazil are observed in October-November. Note that during the solar minimum years EPB detections by GRACE are primarily confined to the longitude sector $270^{\circ}-360^{\circ}$.

It is well-known that high solar fluxes support the formation of plasma bubbles (e.g. Huang et al., 2002; Stolle et al., 2006). For obtaining a more quantitative relation we ana-

Fig. 6. The same as Fig. 5 but for the low solar activity years (20052009).

lyzed the correlation between the EPB occurrence rate and solar flux. Figure 7 shows the globally averaged EPB occurrence rate versus the solar flux index P10.7, defined as $\mathrm{P} 10.7_{i}=\left(\mathrm{F} 10.7_{i}+\mathrm{F} 10.7 \mathrm{~A}\right) / 2$, where $\mathrm{F} 10.7 \mathrm{~A}$ is the average solar flux index of 81 days centered on the current day. In this case we use solar flux bins of $20 \mathrm{sfu}$ for determining the rates. The percentage of passes falling into each P10.7 bin is plotted as dashed line. As we can see, the EPB occurrence rates exhibit a quite linear relationship with $\mathrm{P} 10.7$ over the range P10.7=80-200 both at CHAMP and GRACE altitudes. At CHAMP altitude, the linear equation is $y=0.21 x-11.52$ and for GRACE, it is $y=0.22 x-18.14$, where $y$ is the occurrence rate in percent and $x$ is the solar flux index P10.7. Over the considered solar flux range the linear slope is almost the same for CHAMP and GRACE observations. CHAMP rates, however, are by $5 \%$ higher on average. For solar flux levels above P10.7 = 200 occurrence rates seem to rise nonlinearly in the case of GRACE.

Next we investigate the local time distribution of the occurrence rate. Events are sorted into half-an-hour bins. From Fig. 8 we can see that most of the EPBs are detected before midnight both at CHAMP and GRACE altitudes. For high activity years both increase rapidly after 19:00 LT and reach the highest rates at about 21:30LT. After that the EPBs stay longer until 00:30 LT at CHAMP altitude, while they rapidly decay after 22:00 LT at GRACE altitude. During 

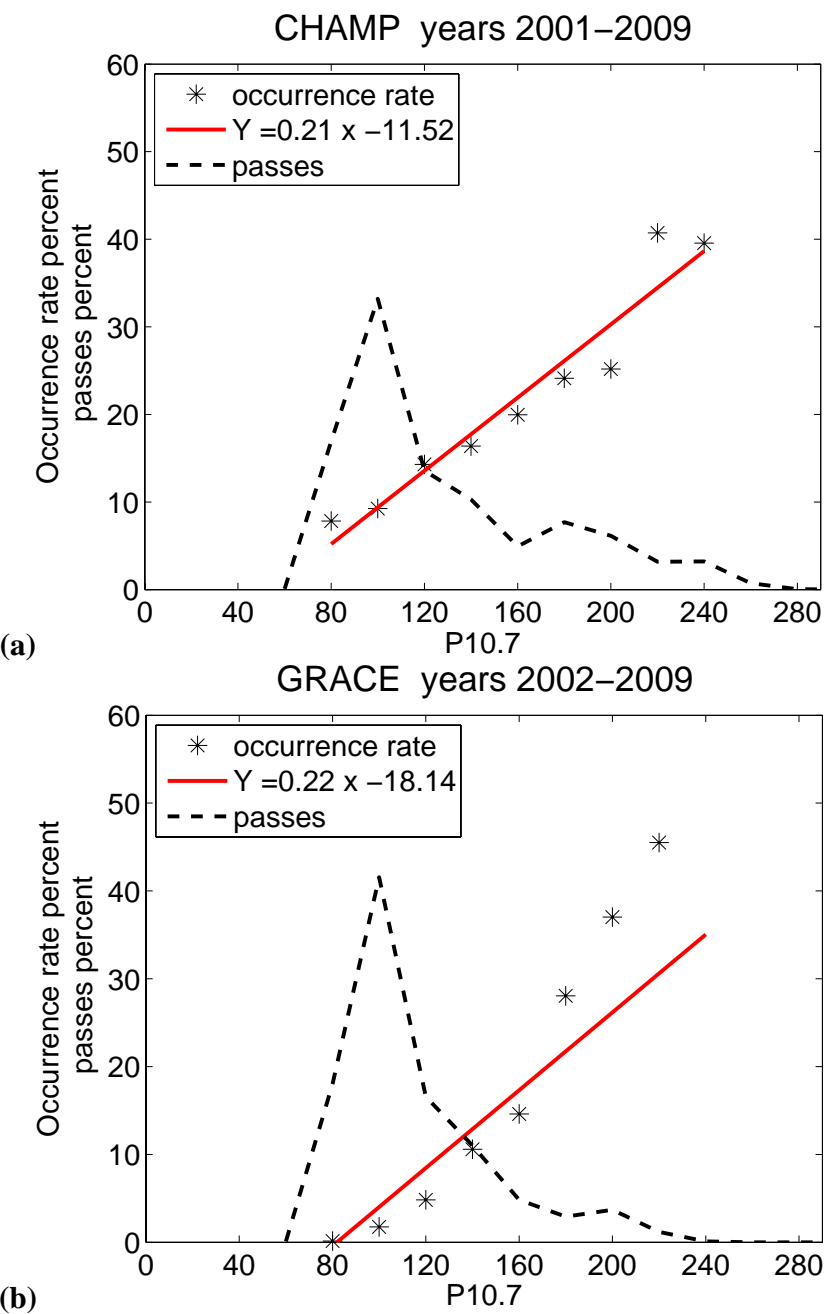

Fig. 7. Occurrence rate of EPBs versus solar flux index P10.7 based on CHMAP (top) and GRACE (bottom) observations. The dashed curve represents the percentage of the equator passes within a certain solar flux level bin, and the straight solid line represents the linear fit to the occurrence rates over the range P10.7=80. . $200 \mathrm{sfu}$.

solar minimum years the increase is gentler after sunset and peak occurrence rates at CHAMP are reached about one hour later, around 22:00 LT. At GRACE the EPB statistic is rather poor for those years.

Now we are interested in the latitudinal distribution of the EPBs. EPBs are sorted into $1^{\circ}$ wide latitude bins. Count numbers in each bin are normalized by the total number of satellite passes. Since the latitudinal extent of a bubble covers only a fraction of the considered $\pm 30^{\circ}$ latitude band, obtained occurrence rates are much smaller than in the other figures. From Fig. 9 we can see that the occurrence rate forms two peaks, north and south of the dip equator. In order to obtain a quantitative description of the distribution we have fitted a Gaussian function separately to the two peaks. The function is specified as $y=A \cdot \exp \left(-\left(x-x_{0}\right)^{2} / 2 \partial^{2}\right)$, where $A$ is the peak amplitude, $x_{0}$ is the latitude of the peak and $\partial$

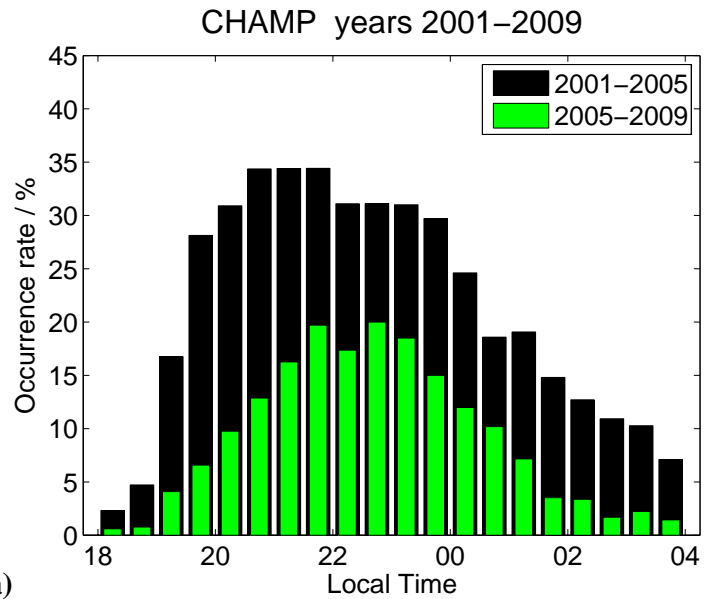

(a)

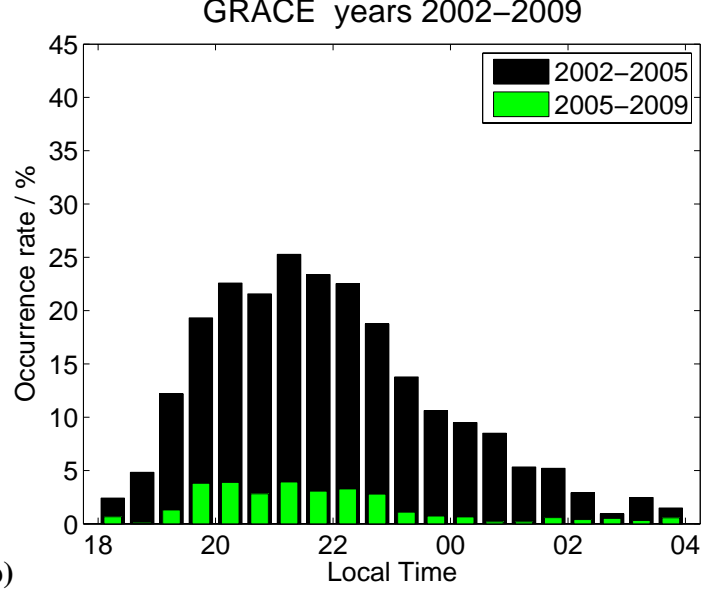

Fig. 8. Occurrence rate distribution of EPBs versus local time based on CHAMP PLP (top) and GRACE KBR (bottom) observation for the two solar activity levels.

is the width in latitude of the distributions. The occurrence distributions are almost symmetrical about the dip equator both at the CHAMP and GRACE altitudes. But during low solar activity years we cannot fit Gaussian curves to GRACE results. In Table 1 the values of the Gaussian fits are listed. Following facts are valid for CHAMP and GRACE: the amplitudes are almost $10 \%$ less at southern than at northern magnetic latitudes. This is the case for both activity levels. Also the occurrence peak is displaced slightly equatorward in the south compared to the north. When comparing CHAMP and GRACE, the EPBs are observed as expected at lower latitudes by the higher spacecraft. During solar minimum years there is also a displacement of the occurrence peaks towards lower latitudes at CHAMP altitude.

Since measurements from the 9 years have been taken at different altitudes, it may be more appropriate to plot occurrence rates versus the L-value of the depleted fluxtube. Figure 10 shows for CHAMP observations that during high solar activity years the occurrence rate peaks at $L=1.085 R_{\mathrm{E}}$ corresponding to a fluxtube apex of $h_{\max }=541 \mathrm{~km}$, while 
Table 1. The value of Gaussian fit and the peak L-value corresponding to Fig. 9.

\begin{tabular}{crrrrrrrr}
\hline & \multicolumn{4}{c}{ CHAMP } & \multicolumn{5}{c}{ GRACE } \\
& SH & NH & SH & NH & SH & NH & SH & NH \\
& solar max & solar max & solar min & solar min & solar max & solar max & solar min & solar min \\
\hline$A$ & $6.46 \%$ & $7.90 \%$ & $2.25 \%$ & $2.73 \%$ & $3.72 \%$ & $4.06 \%$ & - & - \\
$x_{0}$ & $-8.74^{\circ}$ & $9.47^{\circ}$ & $-6.11^{\circ}$ & $6.63^{\circ}$ & $-6.96^{\circ}$ & $8.25^{\circ}$ & - & - \\
$\partial$ & $6.22^{\circ}$ & $6.25^{\circ}$ & $5.58^{\circ}$ & $5.40^{\circ}$ & $6.92^{\circ}$ & $8.37^{\circ}$ & - & - \\
L-value & $1.085 R_{\mathrm{E}}$ & $1.070 R_{\mathrm{E}}$ & $1.085 R_{\mathrm{E}}\left(1.095 R_{\mathrm{E}}\right)$ & - \\
\hline
\end{tabular}

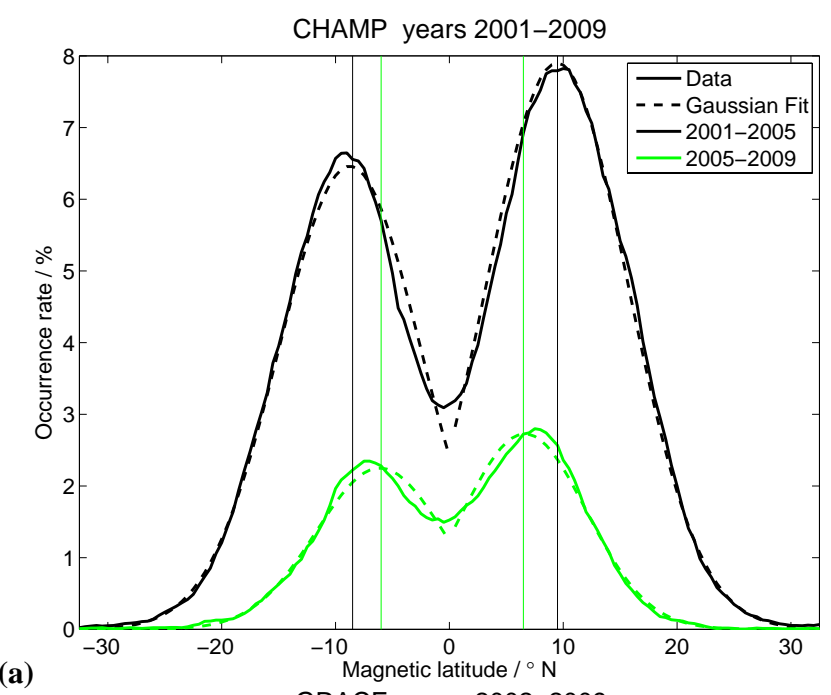

(a)

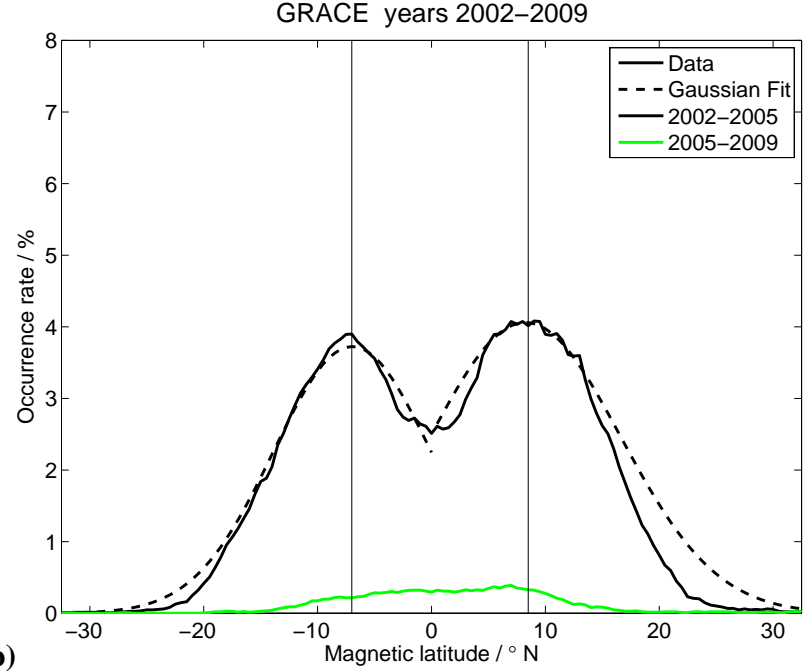

(b)

Fig. 9. Occurrence rates of EPBs versus magnetic latitude based on CHAMP PLP (top) and GRACE KBR (bottom) observations for the two solar activity levels.

during the low solar activity years, highest occurrence rates are observed at $L=1.070 R_{\mathrm{E}}$, which means the fluxtube reaches up to $h_{\max }=446 \mathrm{~km}$. The L-value distribution of GRACE observations is very flat around the maximum ex- hibiting two peaks at 1.085 and $1.095 R_{\mathrm{E}}$ for solar maximum years. The smaller value corresponds to the CHAMP peak. This supports the notion that EPBs form depleted fluxtubes. During solar minimum years no L-value peak is found with GRACE. This is consistent with the apex height of $446 \mathrm{~km}$ deduced from CHAMP data for these years, which is below the cruising height of GRACE.

\section{Discussion}

In the previous section we have presented a statistical study of the occurrence rate of EPBs as deduced from CHAMP PLP and GRACE KBR observations. Based on the many equator crossings of the satellites (more than 5500 per year) we have investigated separately for two altitudes and two solar activity levels the distribution of the EPB occurrence rates with season, local time, magnetic latitude and the dependence on solar flux level. As described in Sect. 3, the data set is restricted to moderately active periods with $\mathrm{Kp}<5.5$ to focus on the non-storm time behavior. This criterion rejects less than $2 \%$ of the passes.

\subsection{The seasonal/local time distribution}

Burke et al. (2004) have shown that there is a general agreement of higher occurrence probabilities at locations where the dusk terminator is parallel to the magnetic meridian. Tsunoda (1985) has argued that the maximum scintillation activity is expected when both ends of the field line are in darkness, minimizing the early evening E-region conductance of the fluxtube, which otherwise would short out the electric fields that promote the R-T instability. Our S/L distribution of EPB occurrence rates deduced from CHAMP during high solar activity years is in general agreement with Fig. 6 of Stolle et al. (2006), which is based on the CHAMP magnetic field data to investigate the climatology of EPB magnetic signatures. The agreement confirms that the depletion of electron density and the EPB magnetic signatures are closely related. An obvious difference between the S/L occurrence patterns deduced from plasma and magnetic signatures appears in the longitude sector $100^{\circ}-130^{\circ} \mathrm{E}$ during spring equinox. The magnetic field method detects almost no 


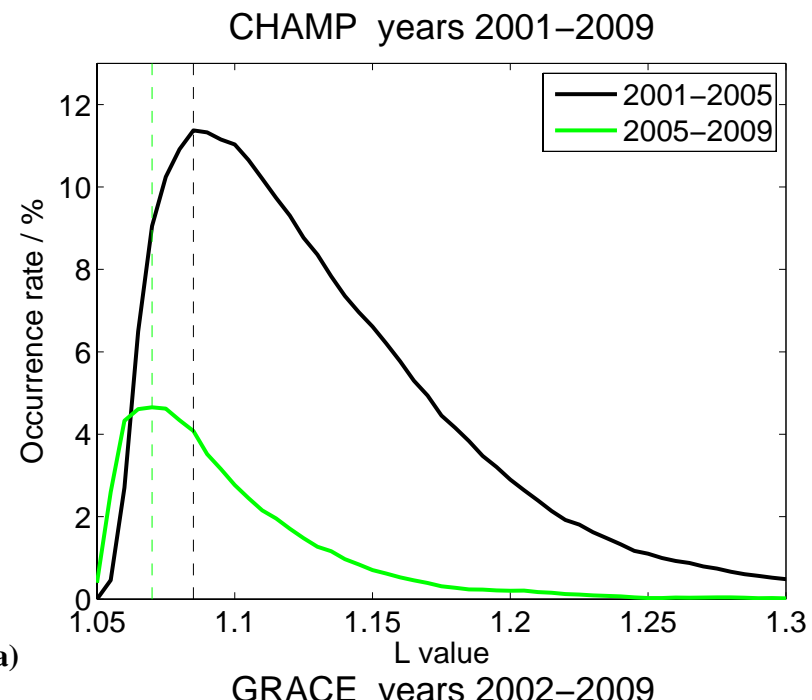

(a)

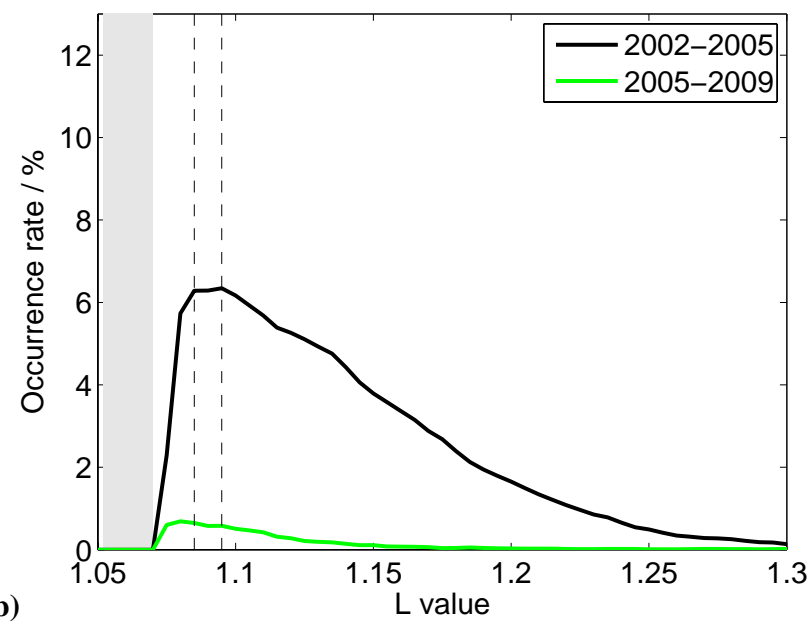

Fig. 10. Occurrence rate of EPBs versus L-value of fluxtube based on CHAMP PLP (top) and GRACE KBR (bottom) observations. The shaded area in the bottom panel represents the range of L-value not sampled by GRACE.

events there in that season while we find occurrence rates of 20\%-30\% (Stolle et al., 2010). Interestingly, such a discrepancy does not appear during northern autumn. We will come back to this issue in Sect. 5.4.

Comparing the EPB distributions derived from CHAMP and GRACE in Figs. 5 and 6 we find a surprisingly high coherence between the two data sets, in particular during the active years. Many detailed features are recorded by both spacecraft although they sample a given region at quite different times. The observed agreement adds confidence in the reliability and comparability of both data sets. Furthermore, we can conclude that the $\mathrm{S} / \mathrm{L}$ distribution follows partly the pattern proposed by Tsunoda (1985) (see Fig. 1 of Burke et al., 2004). The very high occurrence rate over Brazil, however, cannot be explained by it. CHAMP finds highest rates around December solstice during solar active years. This is consistent with the results of Maruyama et al. (1984), Huang et al. (2001), Burke et al. (2004) and Stolle et al. (2006). Interestingly, at GRACE altitude and during low solar activity the activity peak is centered around November. We suggest that the EPBs in December do not reach as high as those in November-October.

\subsection{Dependence on solar flux}

To quantify the solar cycle effect of the EPB activity, Fig. 7 shows the occurrence rates as a function of the solar flux index, P10.7. Quite good linear relationships are revealed both at CHAMP and GRACE altitudes when P10.7 is in the range of 80-200 sfu. For the two independent observations the linear slopes are almost the same, 0.21 and 0.22. Similar results have been found by Huang et al. (2002) and Stolle et al. (2006). From our results, we can see that the solar flux dependence is higher for GRACE especially at high P10.7 values. The linear equations in Fig. 7 can be rewritten. Then we get for the occurrence rates, $y=0.22 \cdot(\mathrm{P} 10.7-55)$ and $y=0.21 \cdot(\mathrm{P} 10.7-82)$ for CHAMP and GRACE, respectively. This implies that only EPBs formed at a solar flux level P10.7>82 sfu can reach the altitude of GRACE. The threshold level for CHAMP altitudes is much lower. For high solar flux levels P10.7>220 the differences between the rates disappear. Then all EPBs seem to reach GRACE heights. This behavior can be explained by the influence of the solar flux on the polarization electric field inside the EPB which helps to push EPBs to greater heights. The polarization Efield inside EPBs can be estimated from the ambient E-field multiplied by the EPB depth, which is defined as the ratio between ambient and EPB plasma density (see Eq. 1 of Laakso et al., 1997). Vichare et al. (2005) and Fejer et al. (2008) showed a linear correlation of the evening equatorial upward plasma drift with solar flux level on the basis of models and observations. Stolle et al. (2008) and Su et al. (2008) have presented global evidence for the linear relationship between the EPB occurrence rate and the vertical plasma drift. Gentile et al. (2006) showed that distribution of EPB depths is rather insensitive to the solar cycle. Every year (i.e. irrespective of solar activity) more than $80 \%$ of EPBs exhibited depth smaller than 10 (see their Table 1). Therefore, the polarization E-field inside EPBs is also expected to increase with increasing solar activity.

\subsection{Local time distribution of EPBs}

As EPBs are known to be post-sunset phenomena, we also investigate the relationship between their occurrence rate and local time at the two altitudes. During high solar activity years, occurrence rates increase rapidly after 19:00 LT at CHAMP and GRACE altitudes, reaching highest rates at about 21:00 LT at CHAMP altitude, while at GRACE, it reaches highest values at about 21:30LT. Both show a decrease after 22:00 LT. Stolle et al. (2006) report a similar 
distribution of EPB versus LT deduced from CHAMP magnetic signatures. At the altitude of ROCSAT- 1 satellite, about $600 \mathrm{~km}$, EPBs rapidly increase at about 20:00 LT and decay after 21:00 LT during moderate to high solar activity years from 1999 to 2004 (Su et al., 2006). During low solar activity years, the EPB occurrence rates at the CHAMP altitude show a much gentler increase after 19:00 LT and decrease after 23:00 LT. GRACE results during solar-minimum years exhibit a rather complex behavior, due to the small number of detections. We will not discuss it in detail.

The general trends in Fig. 8 can be explained as follows. For high solar activity PRE exhibits a large peak around 18:00-20:00 LT (Fejer et al., 2008), which can result in a rapid EPB evolution around the sunset terminator (e.g. Eq. 24 of Sultan, 1996). On the other hand, PRE is small or negligible during solar-minimum years (2005-2009). Burke et al. (2009) argued that EPB evolution during solar minimum can result from the divergence of gravity-driven currents, and that this process is much slower than PRE-related EPB generation. This argument agrees well with our Fig. 8 (left), where the EPB occurrence peaks at later LT during solar minimum years.

\subsection{Latitude distribution of EPBs}

An important aspect of EPBs is their geographical distribution. Having observations at two altitudes allows us to get an idea about the location and shape of the depleted fluxtube. The latitudinal distribution of ESF related magnetic signatures from CHAMP observation peaks at a distance of $\pm 9.5^{\circ}$ in latitude from the dip equator (Stolle et al., 2006). We find a similar latitudinal distribution based on CHAMP PLP observation, which peaks at $-8.74^{\circ}$ and $9.47^{\circ}$ in the Southern and Northern Hemisphere during high solar activity years (e.g. Fig. 9). At the altitude of GRACE the two occurrences rate peaks are closer to the dip equator, which are $-6.96^{\circ}$ and $8.25^{\circ}$ magnetic latitudes. Figure 9 of Burke et al. (2004) shows only one peak of EPB occurrence rates versus magnetic latitude at the altitude of ROCSAT-1 $(600 \mathrm{~km})$ for March and April 2000 and 2002. As indicated in their paper, data from the two years have similar Gaussian-like distributions centered at the magnetic equator. There seems to be an apparent difference between the latitudinal distribution deduced from CHAMP/GRACE and ROCSAT-data. If we assume, however, the depleted region to form along geomagnetic fluxtubes, as supported by the L-values of the occurrence peaks at CHAMP and GRACE, a single maximum is expected for ROCSAT-1. This spacecraft cruises at $600 \mathrm{~km}$ altitude and therefore above the apex height of $540 \mathrm{~km}$ of our peak occurrence fluxtube.

Another difference is the detection approach for EPBs. Most previous studies have used the relative change, $\Delta N_{e} / N_{e}$ as criterion. We use a constant $\Delta N_{e}$ independent of the ambient density for detecting EPBs. At CHAMP altitude the electron density above the dip equator drops sometimes below the resolution of the PLP $\left(<10^{9} \mathrm{~m}^{-3}\right)$. This causes the $\Delta N_{e} / N_{e}$ method to break down. We are also not convinced about the physical relevance of a depletion within such a tenuous plasma. For the mentioned reasons we have selected our detection method, which favours prominent and largescale EPBs due to the sparse sampling ( $15 \mathrm{~s}$ period).

During low solar activity years the two peaks of occurrence rates at CHAMP altitude are closer together than during high solar activity years. At GRACE altitude no clear latitude distribution emerges for the low activity period (green curve in Fig. 9) because of the poor sample statistic. Such a result is consistent with the low apex height of the fluxtube $(446 \mathrm{~km})$ as deduced from CHAMP observations during solar minimum years.

From Figs. 5 and 6 we know, the occurrence rates vary significantly with longitude. For that reason we have determined the latitude distribution at various longitudes. Figure 11 represents the latitude distribution of the EPB occurrence rate separately for four different $90^{\circ}$ wide longitude sectors. It is interesting to note how different the profiles are in the four sectors. Large occurrence rates are deduced, as expected from Fig. 5, in the longitude sectors $270^{\circ}-360^{\circ} \mathrm{E}$ and $0^{\circ}-90^{\circ} \mathrm{E}$. Here we find significantly more events in the Northern Hemisphere. All this is true for CHAMP and GRACE. Within the longitude range $90^{\circ}-270^{\circ} \mathrm{E}$ occurrence rates are much reduced, and the occurrence rate is slightly higher in the south. There the occurrence peaks show up at lower latitudes in CHAMP data, and in case of GRACE the latitude distribution approaches a single-peaked curve, implying that GRACE is cruising at the apex height of the affected fluxtube.

Both our CHAMP and GRACE results are consistent with the notion of EPBs forming plasma depletions along fluxtubes. Larger occurrence rates peak at fluxtubes reaching higher altitudes. This implies that enhanced vertical plasma drift is favoring the formation of EPBs. Such a conclusion is consistent with the results of Stolle et al. (2008) and Su et al. (2008) who found a close relation between the drift velocity during the PRE and the EPB occurrence rate.

Since GRACE detects the least EPBs in the $90^{\circ}-180^{\circ} \mathrm{E}$ longitude sector (see Fig. 11), we may conclude, based on the above arguments, that EPBs are weak in this sector. As mentioned before Stolle et al. (2006) detected significantly less bubbles in the $100^{\circ}-130^{\circ} \mathrm{E}$ longitude range than we do. A plausible explanation may be that the magnetic detection approach is not sensitive enough to capture these weak EPBs.

During solar minimum years much less EPBs are observed. At CHAMP altitude we still detect enough events for a significant statistic. When comparing the black and green curves in Fig. 11 we see that the ratios vary from sector to sector. This ratio is smallest $(\sim 2)$ over longitudes $270^{\circ}-360^{\circ} \mathrm{E}$ and largest $(\sim 6)$ in the sector $90^{\circ}-180^{\circ} \mathrm{E}$. This result is consistent with the occurrence distributions shown in Figs. 5 and 6. Following the conclusion of the previous paragraph it implies that the dependence of EPB occurrence 
(a)
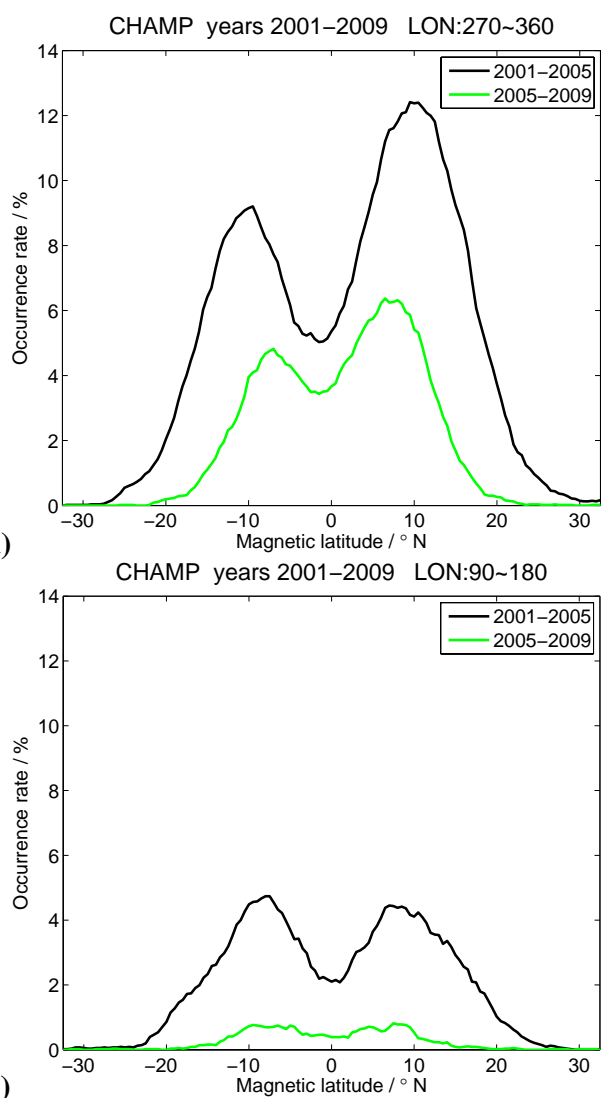

(c)

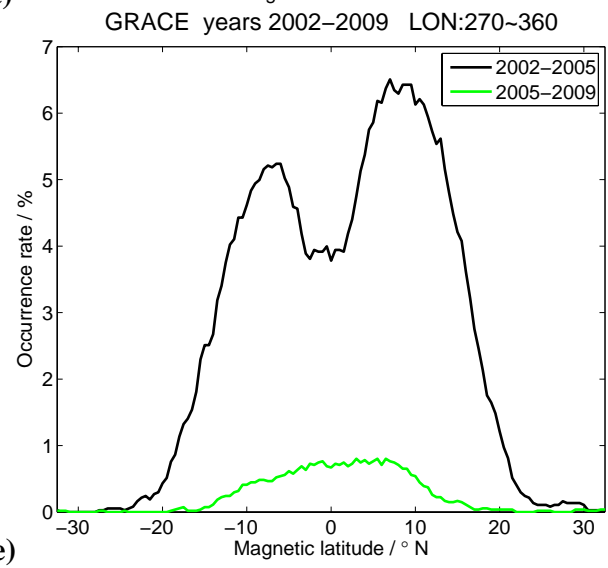

(e)

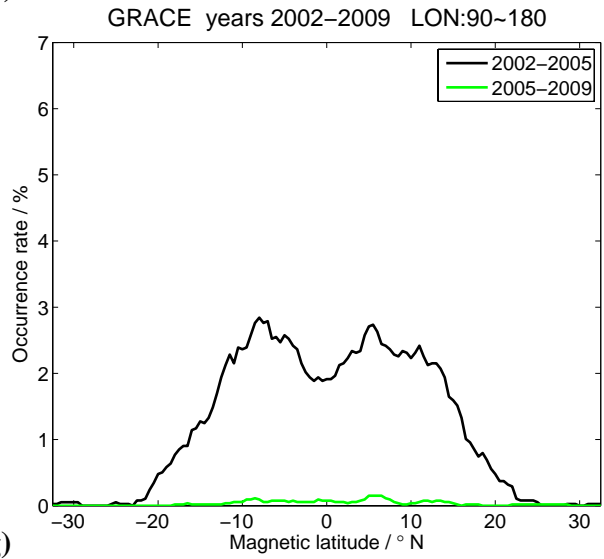

(b)

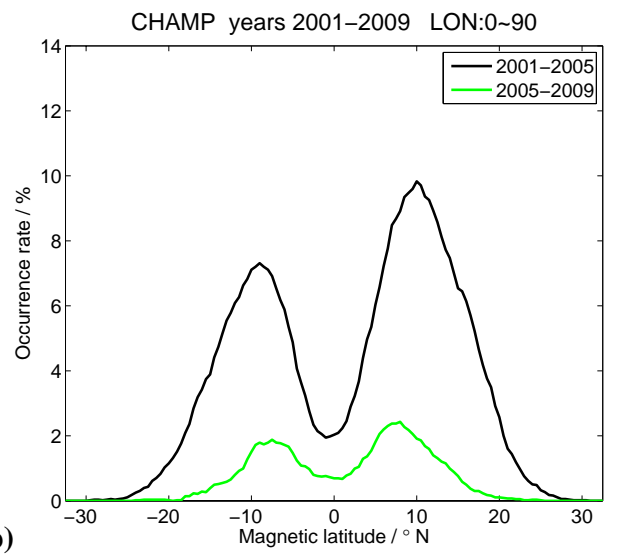

(d)
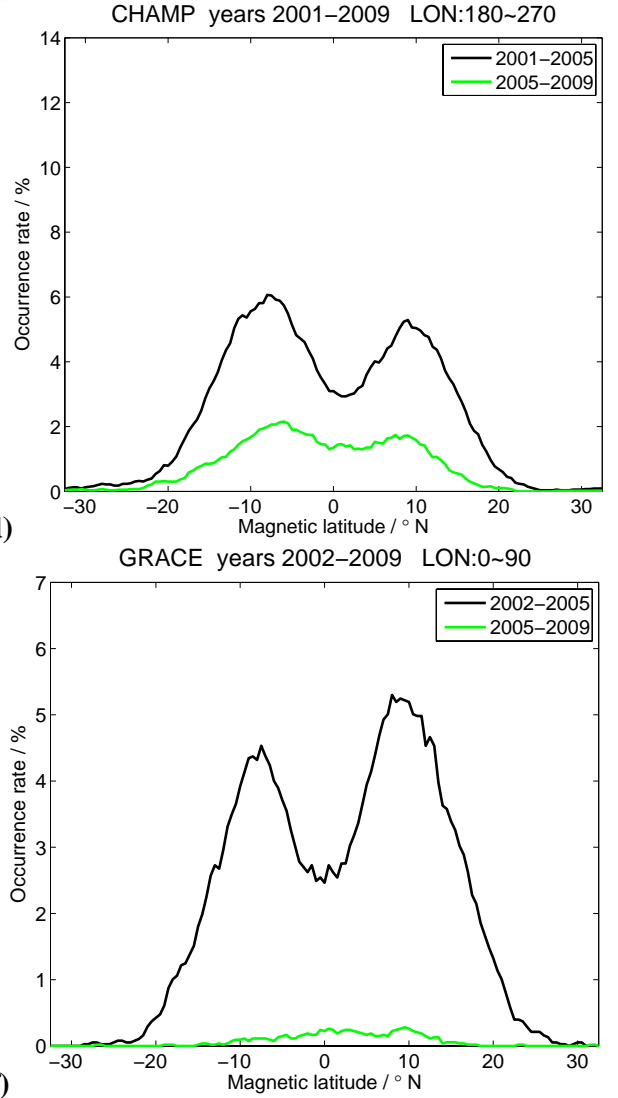

(f)

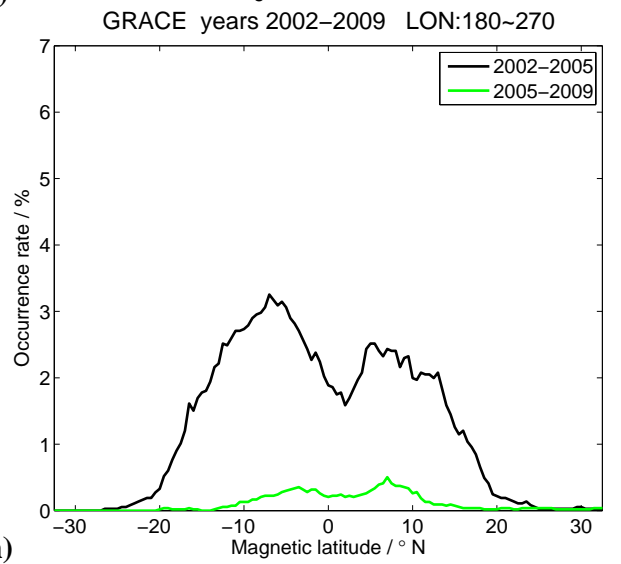

Fig. 11. Same format as Fig. 9, but separate latitude profiles for four longitude sectors. 
(and of the polarization electric field inside EPBs) on solar flux level is longitude dependent. This later suggestion should be verified by more recent missions (e.g. Communications/Navigation Outage Forecasting System, C/NOFS).

\section{Summary}

In this paper we investigated the occurrence rates of equatorial plasma bubbles (EPB) both at CHAMP $(300 \sim 400 \mathrm{~km})$ and GRACE $(\sim 500 \mathrm{~km})$ altitudes from high to low solar activity years. By using the same detection algorithms for EPBs at both spacecrafts a consistent dataset over 9 years is compiled. This allows for detailed and innovative studies of EPB characteristics.

1. The Seasonal/Longitudinal distributions of EPB behave similarly at CHAMP and GRACE altitudes both during high and low solar activity years. As expected the occurrence rate is higher at CHAMP altitude and the maximum rates at CHAMP and GRACE decrease from $70 \%$ to $60 \%$ and from $60 \%$ to $40 \%$ during high to low solar activity years, respectively, above the Brazilian region.

2. Linear relationships between occurrence rates and solar flux index, P10.7, are found at both CHAMP and GRACE altitudes with a linear slope of about 0.21 for P10.7<200 sfu. At higher solar flux levels the occurrence rates at GRACE increase non-linearly. As a consequence the rates at GRACE reach the same level as at CHAMP for P10.7>220 sfu.

3. EPB detection rates increase rapidly after 19:00 LT at CHAMP during high solar flux years and reach a maximum around 21:00 LT. At GRACE the post-sunset increase is a little delayed. During solar minimum years occurrence rate increases more gently and reaches its peak around 2200LT. This implies a slower evolution of the EPBs.

4. The latitudinal distribution of EPB occurrence rates exhibits two peaks symmetrical about the dip equator. The lower peak latitude at GRACE altitude is consistent with the notion that EPBs form a fluxtube of depleted plasma density.

5. A new result is that in longitude sectors of high occurrence rates EPBs are found on fluxtubes which reach to higher apex heights. This supports the suggestion that in regions of enhanced Rayleigh-Taylor instability the polarization electric field inside EPBs pushes the EPBs to greater heights.

6. The dependence of EPB occurrence rate on solar flux level is lowest in the American-Atlantic sector and highest in Indonesian sector. This implies a dependence of the R-T growth rate on the ambient geomagnetic field strength.
These latter two findings should be verified by result from recent and future ionospheric missions.

Acknowledgements. We thank Bela G. Fejer for fruitful discussion about the evolution of equatorial plasma bubbles. The CHAMP and GRACE missions are sponsored by the Space Agency of the German Aerospace Center (DLR) through funds of the Federal Ministry of Economics and Technology. We would like to thank the German Space Operations Center (GSOC) of the German Aerospace Center (DLR) for providing continuously and nearly $100 \%$ of the raw telemetry data of the CHAMP and GRACE satellites. One of the authors (Chao Xiong) is supported by the German Academic Exchange Service (DAAD) and China Scholarship Council (CSC). This study is supported by Doctoral Fund of Ministry of Education of China (Grant No. 200804860012) and National Nature Science Foundation of China (No. 40974087).

Topical Editor K. Kauristie thanks two anonymous referees for their help in evaluating this paper.

\section{References}

Bettadpur, S.: GRACE Product Specification Document, GRACE 327-720, Rev 4.5, 20 February 2007.

Burke, W. J., Gentile, L. C., Huang, C. Y., Valladares, C. E., and $\mathrm{Su}, \mathrm{S}$. Y.: Longitudinal variability of equatorial plasma bubbles observed by DMSP and ROCSAT-1, J. Geophys. Res., 109, A12301, doi:10.1029/2004JA010583, 2004.

Burke, W. J., de La Beaujardière, O., Gentile, L. C., Hunton, D. E., Pfaff, R. F., Roddy, P. A., Su, Y.-J., and Wilson, G. R.: C/NOFS observations of plasma density and electric field irregularities at post-midnight local times, Geophys. Res. Lett., 36, L00C09, doi:10.1029/2009GL038879, 2009.

Case, K., Kruizinga, G., and Wu, S.: GRACE Level 1B Data Product User Handbook, JPL Publication D-22027, 2002.

Fejer, B. G., Scherliess, L., and de Paula, E. R.: Effects of the vertical plasma drift velocity on the generation and evolution of equatorial spread F, J. Geophys. Res., 104, 19859-19870, 1999.

Fejer, B. G., Jensen, J. W., and Su, S.-Y.: Quiet time equatorial $\mathrm{F}$ region vertical plasma drift model derived from ROCSAT-1 observations, J. Geophys. Res., 113, A05304, doi:10.1029/2007JA012801, 2008.

Fowler, W., Bettadpur, S., and Tapley, B.: Mission Planning for the Twin GRACE Satellites, AAS/AIAA Space Flight Mechanics Meeting, Paper AAS 00-164, Clearwater, Florida, 2000

Gentile, L. C., Burke, W. J., and Rich, F. J.: A global climatology for equatorial plasma bubbles in the topside ionosphere, Ann. Geophys., 24, 163-172, doi:10.5194/angeo-24-163-2006, 2006.

Huang, C. M., Richmond, A. D., and Chen, M. Q.: Theoretical effects of geomagnetic activity on low-latitude ionospheric electric fields, J. Geophys. Res., 110, A05312, doi:10.1029/2004JA010994, 2005.

Huang, C.-S. and Kelley, M. C.: Nonlinear evolution of equatorial spread F: 2. Gravity wave seeding of Rayleigh-Taylor instability, J. Geophys. Res., 101, 293-302, 1996.

Huang, C. Y., Burke, W. J., Machuzak, J. S., Gentile, L. C., and Sultan, P.: DMSP observations of equatorial plasma bubbles in the topside ionosphere near solar maximum, J. Geophys. Res., 106, 8131-8142, 2001. 
Huang, C. Y., Burke, W. J., Machuzak, J. S., Gentile, L. C., and Sultan, P. J.: Equatorial plasma bubbles observed by DMSP satellites during a full solar cycle: Toward a global climatology, J. Geophys. Res., 107(A12), 1434, doi:10.1029/2002JA009452, 2002.

Huba, J. D., Joyce, G., and Krall, J.: Three-dimensional equatorial spread F modeling, Geophys. Res. Lett., 35, L10102, doi:10.1029/2008GL033509, 2008.

Kelley, M. C.: The Earth's Ionosphere, Plasma Physics and Electrodynamics, Academic, San Diego Calif., 1989.

Kil, H. and Heelis, R.: Global distribution of density irregularities in the equatorial ionosphere, J. Geophys. Res., 103(A1), 407417, 1998.

Kil, H., Heelis, R. A., Paxton, L. J., and Oh, S.-J.: Formation of a plasma depletion shell in the equatorial ionosphere, J. Geophys. Res., 114, A11302, doi:10.1029/2009JA014369, 2009.

Krall, J., Huba, J. D., and Martinis, C. R.: Three-dimensional modeling of equatorial spread $F$ airglow enhancements, Geophys. Res. Lett., 36, L10103, doi:10.1029/2009GL038441, 2009.

Kim, J.: Simulation Study of a Low-Low Satellite-to-Satellite Tracking Mission, PhD dissertation, Univ. of Texas at Austin, May 2000.

Laakso, H., Maynard, N. C., Pfaff, R. F., Aggson, T. L., Coley, W. R., Janhunen, P., and Herrero, F. A.: Electric field diagnostics of the dynamics of equatorial density depletions, J. Atmos. Terr. Phys., 59, 1626-1631, 1997.

Lühr, H., Maus, S., Rother, M., and Cooke, D.: First in-situ observation of night-time F region currents with the CHAMP satellite, Geophys. Res. Lett., 29(10), 1489, doi:10.1029/2001GL013845, 2002.

Lühr, H., Rother, M., Maus, S., Mai, W., and Cooke, D.: The diamagnetic effect of the equatorial Appleton anomaly: Its characteristics and impact on geomagnetic field modeling, Geophys. Res. Lett., 30(17), 1906, doi:10.1029/2003GL017407, 2003.

Maruyama, T. and Matuura, N.: Longitudinal Variability of Annual Changes in Activity of Equatorial Spread F and Plasma Bubbles, J. Geophys. Res., 89(A12), 10903-10912, 1984.

Mendillo, M. and Tyler, A.: Geometry of Depleted Plasma Regions in the Equatorial Ionosphere, J. Geophys. Res., 88, 5778$5782,1983$.

Mukherjee, G. K.: Studies of the equatorial F-region depletions and dynamics using multiple wavelength nightglow imaging, J. Atmos. Solar-Terr. Phys., 65, 379-390, 2003.

Otsuka, Y., Shiokawa, K., Ogawa, T., Yokoyama, T., Yamamoto, M., and Fukao, S.: Spatial relation of equatorial plasma bubbles and field aligned irregularities observed with an all-sky airglow imager and the Equatorial Atmosphere Radar, Geophys. Res. Lett., 31, L20802, doi:10.1029/2004GL020869, 2004.

Palmroth, M., Laasko, H., Fejer, B. G., and Pfaff Jr., R. F.: DE 2 observations of morningside and eveningside plasma density depletions in the equatorial ionosphere, J. Geophys. Res., 105, 18429-18442, 2000.

Park, J., Min, K. W., Kim, V. P., Kil, H., Lee, J.-J., Kim, H.J., Lee, E., and Lee, D. Y.: Global distribution of equatorial plasma bubbles in the premidnight sector during solar maximum as observed by KOMPSAT-1 and Defense meteorological Satellite Program F15, J. Geophys. Res., 110, A07308, doi:10.1029/2004JA010817, 2005.
Park, J., Stolle, C., Lühr, H., Rother, M., Su, S.-Y., Min, K. W., and Lee, J.-J.: Magnetic signatures and conjugate features of lowlatitude plasma blobs as observed by the CHAMP satellite, J. Geophys. Res., 113, A09313, doi:10.1029/2008JA013211, 2008.

Park, J., Lühr, H., Stolle, C., Rother, M., Min, K. W., and Michaelis, I.: The characteristics of field-aligned currents associated with equatorial plasma bubbles as observed by the CHAMP satellite, Ann. Geophys., 27, 2685-2697, doi:10.5194/angeo-27-26852009, 2009.

Reigber, C., Lühr, H., and Schwintzer, P.: CHAMP mission status, Adv. Space Res., 30, 129-134, 2002.

Retterer, J. M. and Gentile, L. C.: Modeling the climatology of equatorial plasma bubbles observed by DMSP, Radio Sci., 44, RS0A31, doi:10.1029/2008RS004057, 2009.

Scherliess, L. and Fejer, B. G.: Radar and satellite global equatorial F region vertical drift model, J. Geophys. Res., 104, 6829-6842, 1999.

Stolle, C., Lühr, H., Rother, M., and Balasis, G.: Magnetic signatures of equatorial spread $\mathrm{F}$ as observed by the CHAMP satellite, J. Geophys. Res., 111, A02304, doi:10.1029/2005JA011184, 2006.

Stolle, C., Lühr, H., and Fejer, B. G.: Relation between the occurrence rate of ESF and the equatorial vertical plasma drift velocity at sunset derived from global observations, Ann. Geophys., 26, 3979-3988, doi:10.5194/angeo-26-3979-2008, 2008.

Su, S.-Y., Liu, C. H., Ho, H. H., and Chao, C. K.: Distribution characteristics of topside ionospheric density irregularities: Equatorial versus midlatitude regions, J. Geophys. Res., 111, A06305, doi:10.1029/2005JA011330, 2006.

Su, S.-Y., Chao, C. K., Liu, C. H., and Ho, H. H.: Meridional wind effect on anti-solar activity correlation of equatorial density irregularity distribution, J. Geophys. Res., 112, A10305, doi:10.1029/2007JA012261, 2007.

Su, S.-Y., Chao, C. K., and Liu, C. H.: On monthly/seasonal/longitudinal variations of equatorial irregularity occurrences and their relationship with the postsunset vertical drift velocities, J. Geophys. Res., 113, A05307, doi:10.1029/2007JA012809, 2008.

Sultan, P.: Linear theory and modeling of the Rayleigh Taylor instability leading to the occurrence of equatorial spread F, J. Geophys. Res., 101(A12), 26875-26891, 1996.

Tapley, B. D., Bettadpur, S., Watkins, M., and Reigber, C.: The gravity recovery and climate experiment: Mission overview and early results, Geophys. Res. Lett., 31, L09607, doi:10.1029/2004GL019920, 2004.

Tsunoda, R. T.: Control of the seasonal and longitudinal occurrence of equatorial scintillations by the longitudinal gradient in the integrated E region Pederson conductivity, J. Geophys. Res., 90, 447-456, 1985.

Vichare, G. and Richmond, A. D.: Simulation studies of the longitudinal variation of evening vertical ionospheric drifts at the magnetic equator during equinox, J. Geophys. Res., 110, A05304, doi:10.1029/2004JA010720, 2005.

Whalen, J. A.: An equatorial bubble: Its evolution observed in relation to bottomside spread $\mathrm{F}$ and to the Appleton anomaly, J. Geophys. Res., 105, 5303-5315, 2000. 